Advances in Geosciences, 2, 335-338, 2006

SRef-ID: 1680-7359/adgeo/2006-2-335

European Geosciences Union

(c) 2006 Author(s). This work is licensed

under a Creative Commons License.

\title{
Natural risk warning: comparison of two methodologies
}

\author{
A. Cavallo and F. Giannoni \\ Agenzia Regionale per la Protezione dell'Ambiente Ligure, Genova, Italy \\ Received: 18 November 2004 - Revised: 14 September 2005 - Accepted: 14 September 2005 - Published: 4 May 2006
}

\begin{abstract}
The Italian network of "Centri Funzionali" is now reaching operational status both in hydro-meteorological risk forecasting and support to the decision making of administrations that issue natural risk warning. Each centre operates for its district of influence. In order to have a nationwide common standard the National Civil Protection Department proposed a quantitative warning methodology based on the definition of rainfall thresholds correlated to historical damages. In the first phase the thresholds have been defined using two studies that cover all Italy: the VAPI (statistics of extreme rainfall and discharges, see reference) and the AVI (database of historical flood and landslide events and reported damages, see reference). This work presents one year back analysis that compares the new methodology and the one that has been usied since 2000 by the Liguria Region Meteorological Centre with regard to flood warning, pinpointing the performance differences in terms of false and missed alerts.
\end{abstract}

\section{Introduction}

After Law 267/98, a very ambitious project at national level began in Italy, devoted to develop a system called "Sistema nazionale di Centri Funzionali" (CFN). The project was targeted to the defence from hydrogeologic catastrophes and their mitigation. Furthermore this law provided a conspicuous pelf amount for the weather-observation monitoring network improvement over the country. The main task of CFN is to concentrate all the information available (forecasts and observations) in order to issue warnings to the population. Now about a dozen of Centri Funzionali (CF) exists nationwide. In those regions where the $\mathrm{CF}$ is still not self standing the National Civil Protection operates in order to issue warnings in place of the regional CF.

Recently, a new Executive Order (see references) issued by the Italian Prime Minister, sets operational guidelines for

Correspondence to: F. Giannoni

(francesca.giannoni@arpal.org) civil protection purposes in the perspective of CFN. This document identifies the core of the CF; it defines its targets and duties and identifies for each region the warning areas according to region morphology (Ligurian warning areas are depicted in Fig. 1).

The National Civil Protection Department proposed a quantitative methodology (Barbero et al., 2004) based on pluviometric thresholds (associated to their return period) in order to define the rainfall amount that leads to issue warnings for each area. The pluviometric threshold needed to apply this method should be determined according to historical damages. At first stage, at national level, these pluviometric thresholds were defined using VAPI and AVI studies.

In the present work the pluviometric thresholds (Sect. 2) valid for Liguria region were defined performing one-year back analysis (September 2002-September 2003) on data stored in the Ligurian regional damage database (Regione Liguria). The "warning procedure" (Barbero et al., 2004) was then applied for the following year (September 2003September 2004), in order to compare this methodology with the one operationally used by the Ligurian CF pinpointing the performance differences in terms of false and missed alerts (Sect. 3).

The study presented here is performed on a limited period and it will need a more accurate examination. Nevertheless we think it is already important since all the Italian CF are facing this new methodology and this is one of the first works that deals with this topic.

\section{Pluviometric threshold estimation}

It is accepted by the hydrologic community (Siccardi, 1996) that the analysis of historical data has its significance and it is the natural background for risk mapping. In this context pluviometric threshold (PT) are precipitation values potentially critic for the region considered: when rainfall exceeds the threshold value, relevant land effect are expected. In particular according to the "Direttiva", two thresholds need to be 


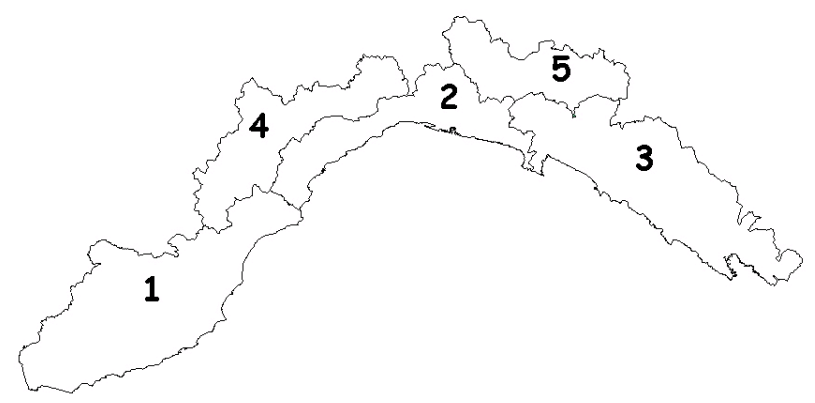

Fig. 1. Ligurian warning areas: 1 West-maritime area, 2 Centalmaritime area, 3 East Maritime area, 4 West Padanian area, 5 East Padanian area.

set: a low risk threshold and a high risk threshold. Moreover, damages are divided into local damages (landslides, soilslip, flash flood events) and areal damages (large areas flood events). Since Liguria region typically suffers from very short and intense rainfall events only local damages were here considered.

Following the procedure described in Barbero et al. (2004), the regional historical damages data-base was analysed to collect events (directly correlated to rainfall) during the study period. Damages were divided into two categories: low and high damages. Following the criterion of closest and/or more representative rain gauge, the corresponding maximum rainfall amount in $3 \mathrm{~h}$ during that particular event was associated to each damage and thereafter, through a statistical analysis (Boni, 1999), a return period was determined for each value.

Since the work is mainly focused on landslides damages the initial conditions have a strong influence. In order to take this influence into account 30-days antecedent rainfall were considered: when the cumulate rainfall amount in the last 30 days exceeds $190 \mathrm{~mm}$, we consider to be in a unstable field according to Cancelli-Nova (1985). According to the status (stable/unstable), the warning is issued for a higher/lower return period. The assumption of using 30 days rainfall depth to determine stability/instability comes from a sensitivity analysis performed within the study. Figure 2 shows for all the damages, the antecedent cumulate rainfall versus its frequency and the stability thresholds for different time windows, according Cancelli-Nova (5, 10, 15, 2030 days). In Fig. 2, increasing the window, which implies an increase of the stability threshold, the number of events that are influenced by the antecedent rainfall increases.

Results of pluviometric threshold estimation are shown in Table 1, where the rainfall threshold return periods obtained in this study are also compared with the ones determined in Barbero et al. (2004). The return periods determined in the present study are lower then the others. This is partially explained by the differences between the two environments analysed: Liguria region has a different morphology characterised by a higher urbanization, in this case even lower rainfall can be responsible for serious land effect.
Table 1. Rainfall return period threshold.

\begin{tabular}{ccccc}
\hline & \multicolumn{2}{c}{$\mathrm{T}$ (years) Liguria region } & \multicolumn{2}{c}{$\mathrm{T}$ (years) Piedmont region } \\
\hline & Unstable field & Stable field & Unstable field & Stable field \\
\hline Low risk & 1.5 & 4 & 2 & 5 \\
High risk & 4 & 10 & 5 & 20 \\
\hline
\end{tabular}

\section{Comparison between two methodologies}

The national warning procedure based on pluviometric thresholds is compared here with the regional hydrologically based one, which is operationally used at the Ligurian CF for the case study, from September 2003 to September 2004. For the entire period, 31 potentially critic events were analysed.

\subsection{National pluviometric based warning procedure}

According to the nationwide warning procedure, a warning must be issued any time the forecast rainfall exceeds the pluviometric threshold determined through a back analysis (Table 1). In doing this, it is necessary to compare consistent time-spatial variables. The forecasted rainfall in $3 \mathrm{~h}-100 \mathrm{~km}^{2}$ is modified using a Areal Reduction Factor (Heredia-Calderon, 1997) and then compared with the local 3-hours pluviometric threshold.

\subsection{Regional hydrologically based warning procedure}

The warning procedure operationally used at the Ligurian CF is based on a meteo-hydrologic real time forecasting chain (Arena et al., 2003). The meteorological forecast is obtained from different tools. The main contribution to the forecasters' activity comes from the combined use of ECMWF Global Circulation Model and Limited Area Model BOLAM (Buzzi and Malguzzi, 1997). BOLAM is run twice a day using initial and boundary conditions derived every $6 \mathrm{~h}$ from ECMWF initialized both at 00:00 UTC and at 12:00 UTC. Each run is performed at two different resolutions: $21 \mathrm{~km}$ and $6,5 \mathrm{~km}$, the latter being self nested every $90 \mathrm{~min}$ in the $21 \mathrm{~km}$ run. The forecasted rainfall field is then used to drive the DRiFt (Giannoni et al., 2000) model in a probabilistic framework, performing multiple runs, not only a deterministic run. DRiFt is a semi-distributed rainfall runoff model based on a morphologic approach, developed to be properly applied to the Liguria region.

Results of the comparison among the two procedures are described in Table 2 . In the study, 31 potentially critic events were analysed. 16 times out of 31, Liguria region, based on the result of the hydrologic forecasting chain, issued a warning to the population. No false alerts were issued and no missing alerts occurred in the study period. In 6 cases the warning was for high risk. If the pluviometric threshold procedure would have been applied only 5 warnings would have been issued and in none of the cases high risk would have been forecasted. 
Cumulated frequency of observed rainfall - all damages

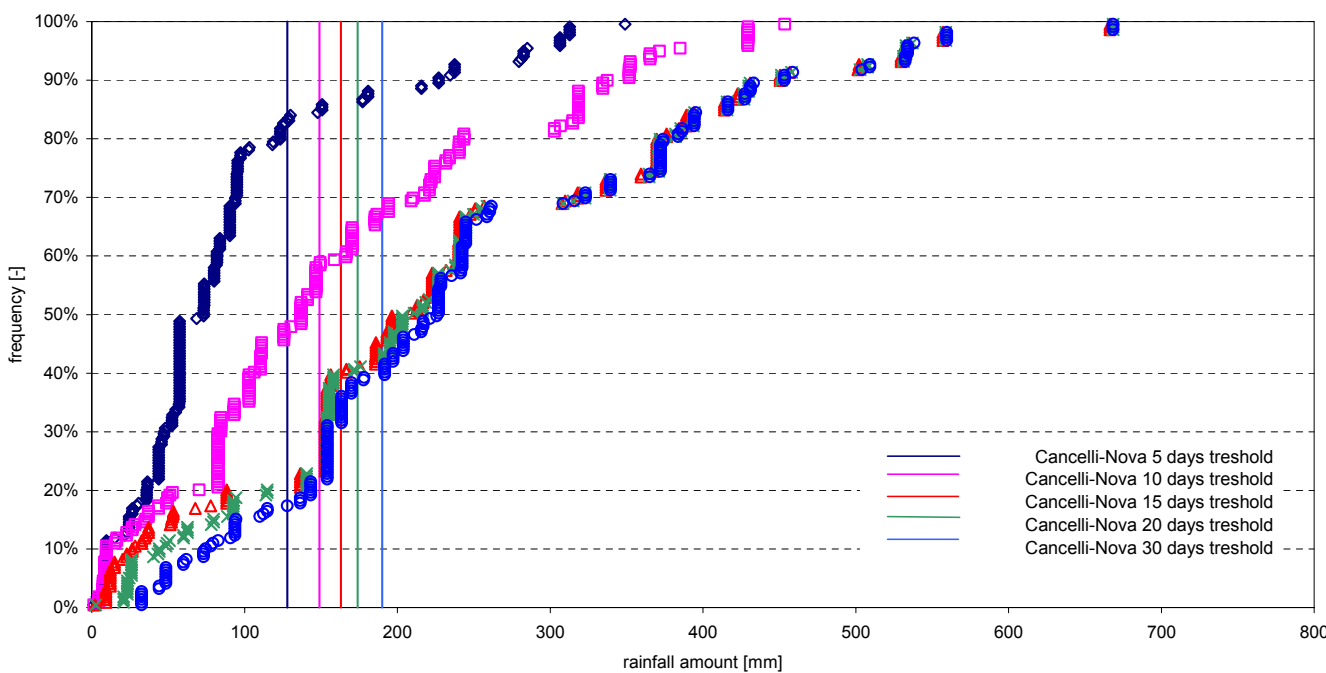

$\diamond$ previous 5 days $\quad \square$ previous 10 days $\quad \Delta$ previous 15 days $\quad \times$ previous 20 days $\quad$ oprevious 30 days

Fig. 2. Sensitivity analysis of the antecedent precipitation.

Table 2. Comparison among the two procedures.

\begin{tabular}{|c|c|c|c|c|c|c|c|c|c|c|}
\hline \multirow[t]{2}{*}{ Data } & \multicolumn{5}{|c|}{$\begin{array}{l}\text { Present Operational Chain } \\
\text { (hydrologic treshold based) }\end{array}$} & \multicolumn{5}{|c|}{$\begin{array}{l}\text { Proposed Operational Chain } \\
\text { (pluviometric treshold based) }\end{array}$} \\
\hline & Area A & Area B & Area C & Area D & Area E & Area A & Area B & Area C & Area D & Area E \\
\hline $18 / 10 / 2003$ & - & - & - & - & - & - & - & - & - & - \\
\hline $19 / 10 / 2003$ & - & - & - & - & - & - & - & - & - & - \\
\hline $30 / 10 / 2003$ & 1 & 1 & 1 & 1 & 1 & - & - & - & - & - \\
\hline $31 / 10 / 2003$ & 2 & 2 & 2 & 2 & 2 & 1 & 1 & 1 & 1 & 1 \\
\hline $01 / 11 / 2003$ & 2 & 2 & 2 & 2 & 2 & - & - & - & - & - \\
\hline $22 / 11 / 2003$ & - & - & - & - & - & - & - & - & - & - \\
\hline $23 / 11 / 2003$ & 1 & 1 & 1 & 1 & 1 & 1 & - & - & - & - \\
\hline $24 / 11 / 2003$ & 1 & 1 & 1 & 1 & 1 & - & 1 & - & 1 & 1 \\
\hline $26 / 11 / 2003$ & 1 & 1 & 1 & 1 & 1 & 1 & - & 1 & - & - \\
\hline $27 / 11 / 2003$ & 1 & 1 & 1 & 1 & 1 & - & - & - & - & - \\
\hline $29 / 11 / 2003$ & - & - & - & - & - & - & - & - & - & - \\
\hline $30 / 11 / 2003$ & 2 & 2 & 2 & 2 & 2 & 1 & 1 & 1 & 1 & 1 \\
\hline $01 / 12 / 2003$ & 2 & 2 & 1 & 2 & 2 & - & - & - & - & - \\
\hline $02 / 12 / 2003$ & 2 & 2 & 1 & 2 & 2 & - & - & - & - & - \\
\hline $03 / 12 / 2003$ & 2 & 2 & 1 & 2 & 2 & - & - & - & - & - \\
\hline $04 / 12 / 2003$ & - & - & - & - & - & - & - & - & - & - \\
\hline $26 / 12 / 2003$ & - & - & - & - & - & - & - & - & - & - \\
\hline $27 / 12 / 2003$ & - & - & - & - & - & - & - & - & - & - \\
\hline $28 / 12 / 2003$ & - & - & - & - & - & - & - & - & - & - \\
\hline $31 / 12 / 2003$ & - & - & - & - & - & - & - & - & - & - \\
\hline $17 / 02 / 2004$ & - & - & - & - & - & - & - & - & - & - \\
\hline $20 / 02 / 2004$ & - & - & - & - & - & - & - & - & - & - \\
\hline $21 / 02 / 2004$ & 1 & - & - & - & - & - & - & - & - & - \\
\hline 06/03/2004 & - & - & - & - & - & - & - & - & - & - \\
\hline 09/03/2004 & - & - & - & - & - & - & - & - & - & - \\
\hline $10 / 03 / 2004$ & - & - & - & - & - & - & - & - & - & - \\
\hline $16 / 04 / 2004$ & - & - & - & - & - & - & - & - & - & - \\
\hline $27 / 04 / 2004$ & 1 & - & - & - & - & - & - & - & - & - \\
\hline $28 / 04 / 2004$ & 1 & 1 & - & - & - & - & - & - & - & - \\
\hline $29 / 04 / 2004$ & 1 & 1 & - & - & - & - & - & - & - & - \\
\hline 03/08/2004 & 1 & - & - & - & - & - & - & - & - & - \\
\hline
\end{tabular}




\section{Conclusions}

The performed work, suggests that the rainfall return period are different in different morphologies. Moreover it is extremely important to perform a specific study for each environment where it has to be applied. In the case of Liguria region return periods estimated through a back-analysis are lower then the ones defined by Piedmont region (see Table 1). Moreover from the comparison among the two warning procedures emerges that 10 warnings would have been missed. Once deeper investigations will be performed, the pluviometric warning procedure could be efficiently applied in parallel to the meteo-hydrologic forecasting chain to issues warnings.

Acknowledgements. This work has been partially supported by the Interreg IIIB, Meddoc Amphore Project.

Edited by: L. Ferraris

Reviewed by: anonymous referees

\section{References}

Arena, N., Cavallo A., Giannoni F., and Turato B.: A operational real time flood forecasting chain, Geophys. Res. Abstr., EAE 03 A10507, EGS-AGU-EUG Assembly, ISSN 1029-7006, 2003.

AVI: avi.gndci.pg.cnr.it.

Barbero, S., Rabbuffetti, D., and Zaccagnino, M.: Una metodologia per la definizione delle soglie pluviometriche a supporto dell'emissione dell'allertamento, $29^{\circ}$ Convegno di Idraulica e Costruzioni Idrauliche, Trento, 2004.
Boni, G.: A physically based regional rainfall frequency analysis: application to a coastal region in Northern Italy, Proc. of EGS Plinius Conference on Mediterranean Storms, Maratea, Italy, 365-376, 1999.

Buzzi, A. and Malguzzi, P.: The BOLAM3 model: recent improvements and results, MAP Newsletter, 7, 98-99, 1997.

Cancelli, A. and Nova, R.: Landslides in soil debris cover triggered by rainstorms in Valtellina (central Alps-Italy), Dep. of Structural Engineering Technical University of Milano, Italy, 1995.

Executive Order: Direttiva del presidente del consiglio dei ministri 27 febbraio 2004, Indirizzi operativi per la gestione organizzativa e funzionale del sistema di allertamento nazionale e regionale per il rischio idrogeologico ed idraulico ai fini di protezione civile, Supplemento ordinario n. 39 della GU 59 del 11.03.04.

De Michele, C. and Rosso, R.: La valutazione delle piene nell'Italia Nord-Occidentale: bacino padano e Liguria tirrenica, CNRGNDCI, 1999.

Giannoni, F., Roth, G., and Rudari, R.: A Semi - Distributed Rainfall - Runoff Model Based on a Geomorphologic Approach, Physics and Chemistry of the Earth, 25/7-8, 665-671, 2000.

Heredia-Calderon, E. A.: Distribuzione spazio temporale delle precipitazioni intense e coefficienti di ragguaglio areale per eventi rari, Genova, 1997.

Siccardi, F.: Rainstorm Hazard and Related Disasters in the NorthWest Mediterranean Region, Remote Sensing Reviews, 14, 5-21, 1996.

VAPI: http://www.gndci.cnr.it/it/vapi/welcome_it.htm. 